\section{Stul polymorphisms in the VWF gene}

\author{
A.Inbal and Robert I. Handin \\ Hematology Division, Brigham and Women's \\ Hospital, 75 Francis Street, Boston, MA 02115, \\ USA
}

Source and Description of Clone: The 368 bp BamHI/SacI fragment of pvWH22 was used as a probe. pvWH22 is a $4 \mathrm{~kb}$ partial cDNA clone for human vWF inserted into pUC 13 (Ginsburg et al., 1985).

Polymorphisms: Two StuI (AGGCCT) (New England Biolabs) polymorphisms identify two invariant bands of $8.4 \mathrm{~kb}$ and 7.0 $\mathrm{kb}$ and four variant bands with alleles at $5.6 \mathrm{~kb}$ (A1) and 4.8 $\mathrm{kb}(\mathrm{A} 2)$ and $3.8 \mathrm{~kb}$ (B1) and $3.3 \mathrm{~kb}$ (B2) (see figure).

Frequency: 23 unrelated caucasian individuals.

$$
\begin{aligned}
& 5.6 \mathrm{~kb}(\mathrm{~A} 1)-0.3 \\
& 4.8 \mathrm{~kb}(\mathrm{~A} 2)-0.7 \\
& 3.8 \mathrm{~kb}(\mathrm{~B} 1)-0.6 \\
& 3.3 \mathrm{~kb}(\mathrm{~B} 2)-0.4
\end{aligned}
$$

There was no evidence for linkage disequilibrium between the two polymorphisms.

Not Polymorphic For: EcoRI, BamHI, SacI, in a panel of 10 unrelated individuals.

Chromosomal Localization: 12p12-12pter (Ginsburg et al., 1985). The 3' region of BamHI/SacI fragment corresponds to the $5^{\prime}$ boundary of an area that could possibly hybridize with similar sequences on human chromosome 22 (Sadler et al., 1987). The region of vWF cDNA contained in the BamHI/SacI fragment corresponds exclusively to sequences on chromosome 12 (Inbal et al., 1989).

Mendelian Inheritance: Co-dominant segregation demonstrated in one family of 11 individuals.

Probe Availability: Available from Robert I.Handin.

Other Comments: No problems on RFLP analysis under normally stringent conditions.

Acknowledgement: This work was supported by NIH P01 HL33014.

References: Ginsburg et al. (1985) Science 228, 1405. 2) Sadler et al. (1987) J. Clin. Invest. 79, 1459. 3)Inbal et al. (1989) Nucl. Acids Res. 17, 10143.

\section{Two polymorphisms at the D10S94 locus}

\author{
A.R.Brooks-Wilson, D.Smailus, S.Myers', \\ L.Anderson ${ }^{1}$, N.E.Simpson ${ }^{1}$ and \\ P.J.Goodfellow \\ Department of Medical Genetics, University of \\ British Columbia, Vancouver, BC and \\ ${ }^{1}$ Departments of Paediatrics and Biology, \\ Queen's University, Kingston, Ontario, Canada
}

Source/Description: A $0.9 \mathrm{~kb}$ DNA sequence isolated by Alu element-mediated PCR from the somatic cell hybrid H2CL1 (Brooks-Wilson et al., 1990) and cloned into the SalI site of pUC18.

Polymorphism: 2 allele codominant polymorphisms identified with PvuII $(\mathrm{A} 1=2.5 \mathrm{~kb}, \mathrm{~A} 2=1.8 \mathrm{~kb})$ and RsaI $(\mathrm{B} 1=8.0$ $\mathrm{kb}, \mathrm{B} 2=7.0 \mathrm{~kb})$.

Allele Frequencies:

A1 0.67

A2 0.3394 chromosomes

B1 0.97

B2 0.0338 chromosomes

Not Polymorphic For: TaqI, MspI, BglII, SacI, HindIII and EcoRI.

Mendelian Inheritance: Codominant inheritance observed in several $M E N 2 A$ kindreds.

Chromosomal Localization: Localized to 10 cen-q11.2 using somatic cell hybrids. Linkage with markers from the pericentromeric region confirms the localization.

Probe Availability: Contact P.J.Goodfellow.

Other Comments: Slight background smear with normal hybridization/washing conditions. Higher stringency conditions required.

Reference: Brooks-Wilson,A.R., Goodfellow,P.N., Povey,S., Nevanlinna,H.A., de Jong,P.J. and Goodfellow,P.J. Rapid cloning and characterization of new DNA markers from the pericentromeric region of chromosome 10 by Alu elementmediated PCR. submitted.

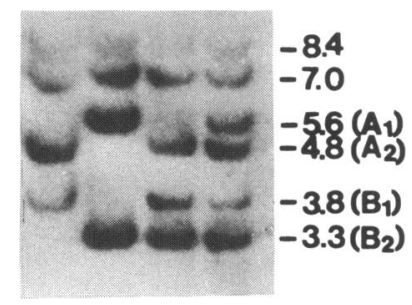

